\title{
SINDICATO, DESENVOLVIMENTO E TRABALHO: crise econômica e ação política no ABC
}

\author{
José Ricardo Ramalho* \\ Iram Jácome Rodrigues *
}

\begin{abstract}
O objetivo deste texto é discutir e problematizar as novas práticas sindicais dos metalúrgicos do ABC paulista, que implicam o envolvimento direto de entidades de representação de trabalhadores em espaços não-fabris, no debate sobre estratégias de desenvolvimento e seus desdobramentos em contextos regionais de uma economia globalizada. Vamos analisar a ação sindical tomando como base dois períodos distintos - décadas de 1990 e 2000 -, e colocar em foco, como síntese desse processo, a realização de um evento político organizado pelo sindicato dos metalúrgicos em 2009, o Seminário "ABC do Diálogo e do Desenvolvimento", que revela as diferentes inserções e perspectivas dos atores sociais locais, regionais e nacionais na busca de alternativas para a crise econômica mundial de 2008. Trata-se de um exemplo de reunião pública que, sem apagar as contradições e os conflitos de uma realidade social marcada pela assimetria de posições na estrutura social, criou um momento de consenso provisório diante das ameaças de uma conjuntura hostil aos trabalhadores.
\end{abstract}

PALAVRas CHAVE: Ação sindical. Desenvolvimento regional. ABC paulista. Crise econômica

A intervenção de sindicatos no debate sobre estratégias de desenvolvimento econômico no Brasil pode ser considerada uma novidade no elenco das habituais demandas associadas às questões salariais e às condições de trabalho. A tentativa de trazer para o espaço público as decisões normalmente tomadas em esferas privadas e a preocupação em avaliar os efeitos sociais dos projetos de investimento que atingem localidades e regiões têm exigido das entidades sindicais, com acúmulo político no mundo do trabalho, uma ação diferenciada de engajamento em disputas de poder e experiências institucionais inovadoras.

$\mathrm{O}$ sindicato dos metalúrgicos do $\mathrm{ABC}$ paulista, pelo protagonismo que exerceu na luta

* Doutor em Ciências Sociais (Ciência Política) e pósdoutorados na Universidade de Londres - UK - e na Universidade de Manchester - UK. Professor titular do Departamento de Sociologia e do Programa de Pós-Graduação em Sociologia e Antropologia da Universidade Federal do Rio de Janeiro - UFRJ.

Largo de São Francisco 1, sala 418, Centro. Cep: 20051070

-Rio de Janeiro-RJ-Brasil. josericardoramalho@gmail.com

* * Doutor em Sociologia e pós-doutoramento pela Universidade de Cambridge - UK. Professor Associado (Livre-Docente) do Departamento de Economia da Universidade de São Paulo e do Programa de Pós-Graduação em Sociologia da Universidade de São Paulo (PPGS-USP). ijrodrig@usp.br de resistência política à ditadura civil-militar instaurada em 1964, e pela experiência histórica de reivindicação por melhores salários e empregos desde o final dos anos 1970, é um bom exemplo de como usar legitimidade e poder de convocação para atuar em instâncias de discussão sobre os problemas criados pelas crises econômicas regionais e para exigir das empresas e dos governos soluções em favor da sociedade local e de seus trabalhadores. ${ }^{1}$

Pelo fato de ser um complexo distrito industrial, berço da indústria automotiva brasileira e com uma concentração de empresas multinacionais e suas redes de fornecedores, o ABC, como território produtivo, foi atingido, nas últimas duas décadas, em especial nos primeiros anos dos 1990 e nos anos finais dos 2000, por crises mundiais (Ramalho e Rodrigues, 2010 e 2007; Ramalho, Rodrigues e Conceição, 2009). Cenários de recessão e diminuição de atividades

${ }^{1}$ Os dados, informações e entrevistas que sustentam o texto são resultados parciais de projetos de pesquisa em andamento, que vêm sendo desenvolvidos pelos autores, apoiados pelo CNPq e pela Faperj (Programa Cientistas do Nosso Estado). 
econômicas são conhecidos dos trabalhadores e dos sindicatos: em geral resultam em aumento do desemprego e pressão empresarial por redução de salário e flexibilização de direitos trabalhistas. A essa intimidação conjuntural, a reação habitual dos sindicatos tem sido a da busca de mecanismos de defesa do emprego, evitando abrir mão de avanços já consolidados. No caso dos metalúrgicos do $\mathrm{ABC}$ não foi diferente, e o sindicato adotou uma linha de ação pró-ativa para atenuar os efeitos negativos das crises e não se furtou a fazer valer o seu poder político para, junto com outros setores, como os pequenos e médios empresários e a administração pública local, discutir propostas de ativação da economia e do emprego regional.

O objetivo deste texto é discutir e problematizar as novas práticas sindicais dos metalúrgicos do $\mathrm{ABC}$, que implicam o envolvimento direto de entidades de representação de trabalhadores em espaços não-fabris, no debate sobre estratégias de desenvolvimento e seus desdobramentos em contextos regionais de uma economia globalizada. Vamos analisar a ação sindical, tomando como base esses dois períodos distintos (décadas de 1990 e 2000), e colocar em foco, como síntese desse processo, a realização de um evento político organizado pelo sindicato dos metalúrgicos em 2009, o Seminário "ABC do Diálogo e do Desenvolvimento", que revela as diferentes inserções e perspectivas dos atores sociais locais, regionais e nacionais na busca de alternativas para a crise econômica mundial de 2008. Trata-se de um exemplo de reunião pública que, sem apagar as contradições e os conflitos de uma realidade social marcada pela assimetria de posições na estrutura social, criou um momento de consenso provisório diante das ameaças de uma conjuntura hostil aos trabalhadores.

O contexto de crise nos anos 1990 e anos 2000 no ABC paulista apresentou diferenças de formato e de impacto sobre a região, assim como encontrou motivações distintas por parte dos governos federais. Em 2008, por exemplo, a presença de Lula na presidência da república desobstruiu os canais de interlocução do governo federal com a região e com o sindicato dos metalúrgicos. Da mesma forma, a participação diferenciada das administrações municipais nos dois períodos é motivo para uma reflexão, tendo em vista que os prefeitos ligados ao Partido dos Trabalhadores inauguraram novas práticas institucionais ao reunir atores sociais diversos, com heranças históricas diversas, em combinações políticas que sinalizaram caminhos pouco explorados de associação e de debate na esfera pública.

\section{UMA DISCUSSÃO TEÓRICA SOBRE MOVI- MENTOSINDICAL}

A estratégia sindical implementada no ABC traz desafios para os trabalhadores, seus representantes e para os estudiosos do tema do sindicalismo. Como explicar uma postura política que implica cooperação institucional com empresários e administração pública, quando, em termos da estrutura social, permanecem inalteradas as contradições irreconciliáveis do capitalismo e as assimetrias que marcam as relações capital/trabalho nas fábricas? O sindicato teria esquecido sua função de representante de classe e deixado de lado a veia de contestação, característica de sua ação nos anos 1970/ 1980? Existem argumentos para justificar essas novas práticas? Houve benefícios concretos para a população trabalhadora do $\mathrm{ABC}$ ?

O sindicalismo metalúrgico do $\mathrm{ABC}$ tornouse, durante os anos 1980, um exemplo do que, no debate mundial sobre novas formas de ação coletiva na área trabalhista, ficou conhecido como "sindicalismo de tipo movimento social" (social movement unionism, conforme o original em inglês), por suas características de contestação política e de associação com outros movimentos sociais (entre outros Moody,1997; Waterman, 1998, 2008; Munck, 2002; Seidman, 1994). Ao longo dos anos 1990, no entanto, com a globalização dos mercados e a imposição de uma reestruturação da produção, este sindicato foi obrigado a adotar uma estratégia defensiva, evoluindo de uma fase mais marcada pelo conflito aberto com as empresas para um processo de "cooperação conflitiva" (Rodrigues, 
1995), situação na qual os trabalhadores, sem abdicar das marcas e diferenças de classe, se viram obrigados a "negociar" as transformações na esfera da produção. A luta pela preservação do seu espaço, enquanto instituição de representação dos trabalhadores nesse novo contexto, levou o sindicato a

[...] se projetar para além das negociações diretas com as empresas", a buscar "uma nova forma de inserção na sociedade, diversificando sua agenda de preocupações, ampliando sua participação em espaços públicos, instituindo novas frentes de ação ${ }^{2}$ (Véras de Oliveira, 2011, p. 286 e 287).

Um modo de problematizar a ação sindical no ABC, tomando como base as várias interpretações existentes na literatura sobre as diferentes fases do sindicalismo, é o de avaliar essas práticas, levando em consideração as particularidades dos contextos sociais, econômicos e políticos, das tradições políticas incorporadas historicamente, das conjunturas econômicas globais e nacionais e seus desdobramentos sobre o mercado de trabalho. Mas, além disso, perceber que os sindicatos estão permanentemente sob pressão de um dualismo universal entre ser uma “organização de negócios” ou uma "expressão e veículo do movimento histórico das classes trabalhadores subalternas" (Fairbrother; Webster, 2008, p. 309-313; Hyman, 2001).

Na avaliação de Fairbrother e Webster (2008, p. 309-313), por exemplo, “os sindicatos são um tipo de movimento social que contém dimensões progressistas e acomodativas" e a questão que se coloca para os analistas é identificar "como e em que circunstâncias os sindicatos podem desafiar e questionar a relação capital/trabalho”. Para esses autores, cabe aos sindicatos, como associações de trabalhadores, regular a relação salário-trabalho e, por essa razão, não podem ignorar o mercado. Mas os sindicatos "são também parte da sociedade, coexistindo com outras instituições e outras constelações de interesses”.

\footnotetext{
${ }^{2}$ Para Véras de Oliveira (2011, p. 270), o I Congresso dos Metalúrgicos do ABC, ocorrido em 1993, foi uma marca importante quando "aprovou-se a participação do Sindicato na campanha denominada Ação da Cidadania contra a Miséria e Pela Vida, que ganhava visibilidade e mobilizava a sociedade". Embalado pelo apelo da campanha ao resgate da cidadania, a resolução do Congresso soou como um manifesto do "sindicato cidadão".
}

Discutir essas estratégias sindicais pós-ditadura, em comparação com exemplos de outros países, é uma boa oportunidade para examinar as especificidades de tempo e espaço, as conjunturas particulares com suas próprias dinâmicas e, ao mesmo tempo, identificar dilemas e práticas que aproximam as ações sindicais diante de conjunturas econômicas desfavoráveis. A contribuição teórica de Hyman (2001, p. 3), ao analisar a experiência europeia diante da reestruturação produtiva, parece-nos adequada para o caso do ABC. Sua sugestão de investigar a ação sindical a partir do triângulo mercado/sociedade/classe, também se aplica ao contexto brasileiro das duas últimas décadas. Para este autor (2001, p. 3-5), todos os sindicatos estão referidos a cada ponto do triângulo: “[...] sindicatos de negócio focam, no mercado; sindicatos integradores, na sociedade; sindicatos de oposição radical, na classe". No entanto, afirma Hyman, os exemplos históricos mostram que os sindicatos, com base em apenas um vértice, ficam instáveis:

[...] sindicalismo de negócio puro raramente ou nunca existiu. Mesmo com a atenção principal voltada para o mercado de trabalho, os sindicatos não podem [...] negligenciar o amplo contexto social e político das relações de mercado. [...].

Do mesmo modo, como veículos deintegração social, os sindicatos podem sustentar uma rationale que justifica sua existência como instituições autônomas, mas essa postura esbarra no fato de que seus membros, como empregados, têm interesses econômicos distintos, "o que pode se chocar com os interesses de outros setores da sociedade”. Por outro lado,

[...] os sindicatos que abraçam uma ideologia de oposição de classe precisam ao menos conseguir uma acomodação tácita com a ordem social existente; e devem também considerar o fato de que normalmente seus membros esperam que seus interesses econômicos de curto prazo sejam adequadamente representados.

Sem desconsiderar a perspectiva macro de análise, que problematiza a estrutura de classes da sociedade capitalista e as estratégias das empre- 
sas, a intenção do nosso texto é enfatizar a capacidade de agência dos trabalhadores organizados e o seu poder coletivo de alterar disputas políticas em arenas locais. Embora as empresas multinacionais tenham sua lógica de acumulação articulada globalmente, os territórios produtivos, que constituem seus elos locais, são arenas políticas de disputa de poder, onde os atores sociais exercem sua capacidade de contestar decisões de investimento e projetos de desenvolvimento econômico. Como Olivier de Sardan (2005, p. 183-186), consideramos que estes atores têm "recursos de poder desiguais e desequilibrados”, mas não estão, nunca, “destituídos de poder".

\section{UMA VOLTA AO PASSADO RECENTE: a crise dos anos 1990 e a reação sindical}

A participação do sindicato dos metalúrgicos na organização e liderança de uma iniciativa do tipo do Seminário "ABC do Diálogo e do Desenvolvimento", na verdade, permite remontar a uma história que começa no início dos anos 1990. O ABC, nesse período, segundo Conceição (2008),

[...] vivenciou, de modo mais agudo que no restante do país, a reestruturação industrial, cujo resultado foi, entre outros, a desnacionalização do capital, a falência de inúmeras empresas, a desativação de várias fábricas de grande, médio e pequeno porte, a redução de cerca de $50 \%$ dos postos de trabalho.

E a crise serviu para que empresários justificassem o deslocamento para outras regiões, especialmente por causa do "regime automotivo" de 1995, e colocassem a responsabilidade exatamente na intensidade da atividade sindical.

O processo de reestruturação produtiva é extremamente perverso quando não acompanhado por um movimento sindical que procure minimizar os seus efeitos redutores de mão de obra e de mercado. A ausência de crescimento econômico é o pior dos mundos. Você vive a demissão da reestruturação aliada a não geração de emprego pela ausência de crescimento econômico. Então discutimos a reestruturação produtiva para minimizar seus efeitos ou buscar ao menos interromper o curso natural do que seria o investimento do capital. Mas estamos preocupados também com o desenvolvimento que é na sequência a contrapartida de geração de emprego, de recolocação de pessoas e de ampliação do próprio mercado. Isso é o que tem nos levado a uma preocupação com política industrial, com políticas setoriais, com desenvolvimento local (José Lopes Feijó, Presidente do Sindicato dos Metalúrgicos do ABC, 18/06/2004).

No entender de Abrucio e Soares (2001, p. 152-156), a crise no ABC dos anos 1990 fez com que os atores locais fossem "tomando uma postura de organizar-se regionalmente”. Segundo esses autores,

[...] nem todos os grupos atuaram (com a) mesma intensidade, [...] bem como nem todas as questões tiveram o mesmo potencial agregador". Mas as dificuldades econômicas colocaram a região sob um dilema: "ou reagia coletivamente, ou se corria o risco de todos perderem, em proporções diferentes, porém com um impacto de soma-negativa no geral.

Esse processo coincide, também, com as mudanças resultantes das eleições municipais de 1988, com a posse de novos grupos políticos, especialmente aqueles ligados ao Partido dos Trabalhadores. ${ }^{3}$ Para o ex-prefeito do PT, Celso Daniel (2001b, p. 78 e 79), o principal formulador e realizador das novas propostas de articulação para o desenvolvimento regional,

[...] a crescente consciência coletiva da crise estrutural do Grande ABC - em substituição à ausência de tal consciência na década de $1980-$ criou condições para a constituição de complexa institucionalidade regional.

Para Daniel, a superação da crise não poderia estar baseada em decisões exógenas à região e fazia-se necessário

\footnotetext{
"É bom recordar, ainda, que o diagnóstico sobre a situação regional não era o ponto mais importante no discurso dos petistas [...]. Foi com a assunção ao poder e o enfrentamento de seus problemas, numa época marcada pelo acirramento e conscientização de dimensão da crise econômica e social do ABC, atingindo em cheio um modelo de desenvolvimento bem sucedido por trinta anos, que os prefeitos petistas procuraram atuar em prol da temática regional“ (Abrucio e Soares, 2001, p. 152-156).
} 
uma proposta alternativa de desenvolvimento local endógeno, isto é, calcado, sobretudo em decisões tomadas internamente à região, pelos seus protagonistas, ou ao menos fortemente influenciadas por estes últimos". ${ }^{4}$

Uma primeira reação institucional à crise da indústria no ABC foi a criação da Câmara Setorial da Indústria Automobilística pelo governo federal (entre outros, Arbix, 1996 e 1997; Oliveira, 1992 e 1993; Diniz, 1993; Cardoso e Comin, 1995 e Cardoso, 1999a; Bresciani e Benites Filho, 1995; Anderson, 1999; Silva, 1997). Experiência nova, pelo exercício de um mecanismo democrático de gestão pública setorial, que reuniu sindicatos, empresas e governo para elaborar saídas para a redução das atividades do setor e para o desemprego, representou um aprendizado para o sindicato dos metalúrgicos.

Entre as diversas iniciativas articuladas na região do $\mathrm{ABC}$ destaca-se, inicialmente, o papel desempenhado pelos prefeitos na organização do Consórcio Intermunicipal do ABC, de 1990, reunindo sete municípios, com o objetivo de atuar de modo integrado no tratamento dos temas de interesse comum, em especial no que tange à infraestrutura, desenvolvimento econômico e meio-ambiente (entre outros Daniel, 2001a; Abrucio \& Soares, 2001; Reis, 2005; também http://www.consorcioabc.org.br).

O outro exemplo foi a criação, em 1994, do Fórum da Cidadania do Grande ABC, que articulou setores da sociedade civil regional para priorizar, nas eleições municipais, o voto nos candidatos da

${ }^{4}$ Para Abrucio e Soares (2001, p. 128 e 129), embora a região do ABC apresentasse as características principais das metrópoles brasileiras, com o seu desenvolvimento industrial e urbano desordenado, desigual e concentrado, houve, também, razões para a consolidação de uma identidade regional devido: “a) fator histórico - até meados do século XX todo o território que abriga hoje o ABC era apenas um município; b) fator geográfico - $[. .$. como fator agregador a situação da área de mananciais, que abrange todos os municípios e ocupa mais de $50 \%$ do território regional; c) fator econômico - a industrialização nas décadas de 1960 e 70 definiu um perfil econômico para a região, assim como a crise a partir da década de 1980 [...] impacta de forma direta ou indireta, todos os municípios do ABC; d) fator social e político - os movimentos sociais, o novo sindicalismo e o nascimento do PT nas décadas de 1970 e 80 enfatizaram uma cultura associativista e politizada; e) fator cultural - ao longo dos últimos anos vem se reforçando o sentimento dos atores sociais de pertencerem a uma região, de compartilharem uma identidade regional”. região, em movimento que ficou conhecido como "vote no Grande ABC" (Petrolli, 2000; Horta, 2003)..$^{5}$ O Fórum se institucionalizou em seguida e agregou cerca de 80 entidades (associações empresariais da indústria e do comércio, sindicatos de trabalhadores, representações da mídia local, organizações não governamentais etc.), com o objetivo de produzir subsídios para resolver os problemas regionais.

Mas a experiência mais completa e reveladora da busca institucionalizada de alternativas para a crise econômica trazida pela reestruturação industrial ocorreu com a constituição da Câmara Regional do ABC, em 1997, diferenciada do Consórcio Intermunicipal e do Fórum da Cidadania pela tentativa de juntar em uma mesma instância de discussão atores públicos e da sociedade civil (entre outros, Daniel \& Somekh, 1999 e 2001; Gomes, 1999; Leite, 1999; Guimarães, Comim e Leite, 2001; Boniface, 2001; Klink, 2000 e 2001; Albuquerque, 2001; Camargo, 2003; Bresciani, 2004). ${ }^{6}$

O desdobramento das atividades da Câmara Regional resultou na constituição, em 1998, da Agência de Desenvolvimento Econômico do Grande ABC, uma instituição não governamental, sem fins lucrativos, com a missão de dar suporte institucional aos acordos debatidos dentro da Câmara. ${ }^{7}$

A Agência de Desenvolvimento Econômico, hoje, é a entidade mais forte, abaixo do Consórcio [Intermunicipal], que faz gestão de projetos, pro-

${ }^{5}$ Nas eleições de 1994, a Região do ABC elegeu cinco deputados federais e oito deputados estaduais, o que foi a maior representação parlamentar observada em sua história até aquele momento.

${ }^{6}$ Os componentes da Câmara Regional do ABC, na segunda metade da década de 1990, foram: o Governo do Estado de São Paulo, o Consórcio Intermunicipal (sete prefeituras), os legislativos municipais, os parlamentares do ABC na Assembleia Legislativa e no Congresso Nacional, o Fórum da Cidadania, as associações empresariais e os sindicatos de trabalhadores.

${ }^{7}$ A Agência tem como sócios o Consórcio Intermunicipal (que envolve as sete Prefeituras); as quatro diretorias regionais do Centro de Indústrias do Estado de São Paulo (CIESP); as Associações Comerciais e Industriais dos sete Municípios; os Sindicatos de Trabalhadores (Sindicato dos Metalúrgicos do ABC, Sindicato dos Químicos do ABC, Sindicato das Costureiras, Sindicato da Construção Civil); o Serviço de Apoio às Micro e Pequenas Empresas (SEBRAE), as empresas do pólo petroquímico regional (Petroquímica União, Solvay, Cabot, Polietilenos União, Polibrasil, Crevron, Oxicap e Petrobrás) e as universidades (IMES, UNI-A, Fundação Santo André, UNIBAN, UNIABC, Metodista, FOCO). 
move o debate, que recebe os setores... A Agência é composta por trabalhadores, por empresários, por universidades, e pelos prefeitos. O Consórcio tem 49\% do direito a voto na Agência... . Os demais setores: universidades, empresários e trabalhadores têm os outros 51\% (Rafael Marques, Vice-Presidente do Sindicato dos Metalúrgicos do ABC, em 24/02/2010).

Essas iniciativas podem ser vistas como um esforço coletivo de fugir da decadência econômica e apresentaram alguns desdobramentos positivos. Nos anos 2000, verificou-se uma retomada dos níveis de produção e da atividade econômica no setor metalúrgico. Menos fábricas foram fechadas e reduziu-se o deslocamento de empresas para outros municípios. O emprego formal cresceu em cerca de 35\%, entre 1999 e 2005, e em 16\%, no caso específico do setor industrial , segundo dados da RAIS-CAGED; e a taxa de desemprego caiu do patamar de 21\% em 1999, para 16\% em 2005 (PED/SEADE/DIEESE).

Todo esse processo de renovação institucional teve a participação decisiva dos sindicatos da região, em particular do sindicato dos metalúrgicos. Para Abrucio e Soares (2001, p. 152156), "ao longo da transição e redemocratização do país, os sindicatos tornam-se o principal personagem da cena política da região e estabelecem uma feição muito peculiar, de contínua mobilização, a este espaço político territorial [...]”.

De fato, o sindicalismo do ABC inaugurava uma prática sindical nova ao incluir nas suas preocupações políticas as questões sociais que afloravam com a crise econômica regional. Desse contexto surgiu, inclusive, a denominação de "sindicato cidadão" (Véras de Oliveira, 2011, Rodrigues, 2006 e 2011, entre outros) para definir essas atividades sindicais, além de ter se transformado em referência no debate político da principal central sindical do país, a Central Única dos Trabalhadores - CUT.

E o sindicato está voltado hoje para as ações de cidadania, ou seja, pensar trabalhador e trabalhadora como cidadão [...]. Ser trabalhador e trabalhadora é parte do tempo. A integralidade do tempo é cidadania. Então, meio ambiente, política de gênero, raça, questão de etnia, [...] contra o trabalho infantil, exploração sexual, abuso se- xual de criança e adolescente... [...] Então um sindicato voltado pra uma concepção de plenitude cidadã. Então eu diria que nós continuamos alicerçados num forte processo de organização, capacidade e mobilização, de clareza com relação às nossas lutas, nossas maneiras, nossos objetivos e, envolvidos com a comunidade, com as necessidades da cidadania e, sintonizado com a necessidade de desenvolvimento que a região precisa, que o Brasil precisa e que resulta em emprego (José Lopes Feijó, Presidente do Sindicato dos Metalúrgicos do ABC, 18/06/2004).

A novidade desse processo está na inclusão da economia como um todo e dos projetos de desenvolvimento regional em particular, como temas importantes da pauta sindical e na ampliação e responsabilidade dos sindicatos sobre os destinos do território produtivo e dos trabalhadores. Nesse contexto, ocorreu a incorporação da discussão sobre a "regionalidade", ou seja, a introdução de uma preocupação com as consequências das políticas macroeconômicas para a vida dos trabalhadores do ABC. Segundo Conceição (2008),

nesse processo o Sindicato dos Metalúrgicos do $\mathrm{ABC}$ criou o entendimento de que era necessário empreender esforços para influir na área das políticas públicas, tendo em vista sua importância no nível de produção e emprego. [...] Um dos marcos da ação sindical em relação ao tema da região foi a elaboração, em novembro de 1995, da publicação "Rumos do ABC: a economia do $A B C$ na visão dos metalúrgicos".

Neste trabalho, elaborado pela Subseção do DIEESE do Sindicato dos Metalúrgicos do ABC, realizou-se diagnóstico de alguns dos obstáculos enfrentados pela economia local e foram apresentadas algumas diretrizes gerais para uma política de desenvolvimento da Região (Camargo, 2003; Bresciani, 2004.).

\section{A CRISE ECONÔMICA DOS ANOS 2000}

A segunda crise econômica a atingir a região do ABC e seu parque industrial, em 2008, teve características diferentes daquela ocorrida ao longo da década de 1990, e o corte nos empregos deveu-se a uma falência dos mecanismos do capi- 
tal financeiro internacional, com desdobramentos prejudiciais para a economia das empresas, especialmente as da indústria. Os atores políticos da arena regional eram os mesmos, mas, nesse novo contexto, o protagonismo dos sindicatos, especialmente do sindicato dos metalúrgicos (o mais atingido pelas demissões) foi decisivo para uma mobilização em busca de alternativas para reverter o desemprego. Isto se deveu, não só ao acúmulo de práticas de discussão em instâncias como a Agência de Desenvolvimento Regional do ABC, mas, também, à proximidade política dos dirigentes sindicais metalúrgicos com a administração pública regional e nacional que viabilizaram iniciativas como o Seminário ABC do Diálogo e do Desenvolvimento.

A participaçãono debate sobre desenvolvimento e economia regional foi definitivamente incorporadaà pauta sindical e se traduziu em documentos como o do VI Congresso dos Metalúrgicos do ABC (Construindo um Brasil justo e democrático: emprego e trabalho decente), ocorrido em maio de 2009:

Os atores regionais, entre eles os sindicatos, de-
vem colocar em debate o próprio modelo de de-
senvolvimento que se quer para a região, cujos
elementos básicos devem ressaltar: aquele que,
primeiro combina crescimento econômico com
inclusão social e proteção ao meio ambiente; se-
gundo, que promove uma nova cultura empresa-
rial, baseada na democratização das relações
capital-trabalho e na responsabilidade social das
empresas; terceiro, que estimula formas inova-
doras de mobilização dos recursos econômicos
através de redes de pequenas empresas, cuja
sustentabilidade (social, técnica e institucional)
é assegurada a partir dos efeitos sistêmicos (aglo-
meração e proximidade) proporcionados pelos
territórios em que as redes operam (Construindo
um Brasil justo e democrático: emprego e traba-
lho decente - VI Congresso dos Metalúrgicos do
ABC. Caderno de teses, 2009, p.42).

Se, por um lado, houve um maior envolvimento dos trabalhadores, através do sindicato, na cruzada por alternativas para o modelo de desenvolvimento estabelecido e origem da crise econômica, o mesmo não pode ser dito do setor empresarial, dividido em termos de estratégias gerenciais e tamanho do negócio. Pode-se dizer que houve uma variação significativa de perspectivas. Assim, enquanto os pequenos e médios empresá- rios, que têm menos mobilidade e dependem dos arranjos produtivos locais para o sucesso dos seus negócios, tiveram um engajamento efetivo nas novas articulações, as empresas multinacionais, habitualmente não envolvidas em negociações e planos desenvolvidos a partir do espaço regional ou local, mas beneficiadas pelas medidas de incentivo fiscal estabelecidas pelo governo federal como forma de reativar a economia industrial e preservar os empregos, tiveram uma atuação tímida diante das novas iniciativas. Na verdade, a discussão sobre a revitalização industrial do ABC exigiu um compromisso que questionava as diretrizes estabelecidas pelas matrizes localizadas fora do Brasil.

As dificuldades no relacionamento com as multinacionais da indústria automotiva permanecem e demonstram uma divergência de perspectiva empresarial no que diz respeito aos vínculos e ao enraizamento no território produtivo. As iniciativas locais e regionais de discutir alternativas para as crises econômicas acabaram por criar situações de constrangimento ao demandar um compromisso em termos de participação e de contrapartidas econômicas e sociais.

Há uma dificuldade em convencer esse empresariado multinacional. [...] As montadoras não têm uma concepção regional, elas não acreditam nisso. Preferem não ter essa concepção para não ficar amarradas a uma determinada região. Elas querem ter a liberdade de transitar hoje não mais pelo país, mas pelo mundo do jeito que quiser. Então hoje, as montadoras, a gente não consegue trazer eles para o debate. Para elas [...] é tudo como se fosse uma concessão. $\mathrm{O}$ emprego é uma concessão, o ICMS, os impostos municipais, estaduais que ela paga, é um favor que ela está prestando a sociedade. Essa é a visão que elas têm (Wagner Santana, Secretário Geral do Sindicato dos Metalúrgicos do ABC, 2013).

O poder de convocação investido no sindicato nesse contexto lhe confere legitimidade para acionar outras instituições e atores que são essenciais para a construção de uma proposta de desenvolvimento regional. É o caso da relação com a recentemente criada Universidade Federal do ABC:

As universidades participam, mas não com todo o potencial que elas têm. Mas algumas estão se 
incorporando mais, o que pode ajudar. [...] Olha que a UFABC é nova aqui na região, mas nós estamos forçando a UFABC. Eu faço parte também de conselho universitário, e quando consigo ir nas reuniões, o meu discurso é: a Federal tem que se relacionar com a sociedade. [...] Então está se criando essa massa crítica importante na UFABC, que pode gerar bons frutos para a região (Rafael Marques, Vice-Presidente do Sindicato dos Metalúrgicos do ABC, em 24/02/2010).

A articulação sindical, se ainda carece de políticas regionais mais estáveis, proporcionou uma reação ao desemprego ocasionado pela crise. Segundo o jornal ABCD Maior, ${ }^{8}$ o ABCD tinha criado, já em agosto de 2009, mais de cinco mil novos postos de trabalho, revertendo a queda dos meses anteriores. E, para confirmar essa inserção regional, o atual presidente do Sindicato dos Metalúrgicos do ABC, Rafael Marques, foi eleito em 2013 para o cargo de presidente da Agência de Desenvolvimento Econômico do Grande ABC.

É a primeira vez que um sindicalista assumirá a direção da agência, criada em 1998 a partir da união entre instituições públicas e privadas dos sete municípios da região [...]. O vice-presidente na próxima gestão, representante do meio acadêmico, será o [...] pró-reitor de extensão da Universidade Municipal de São Caetano do Sul. [...] O presidente eleito destacou o fato inédito de um representante do movimento sindical assumir a presidência pela primeira vez. "E assumimos numa composição tão importante, pioneira, junto com a universidade. Uma união do trabalho com o conhecimento, ambos fundamentais para o desenvolvimento econômico", afirmou [...]". ("Metalúrgico assumirá comando da Agência de Desenvolvimento Econômico do ABC”, Rede Brasil Atual, 26/03/2013).

8 “Os dados do Caged (Cadastro Geral de Empregados e Desempregados), divulgados nesta quarta-feira (16/09/ 2009) pelo Ministério do Trabalho, representam um salto na criação de emprego na Região, já que em julho o resultado ainda era negativo [...]. Agosto [...] marcou a recuperação do emprego nas indústrias de transformação da Região. [...] Vale destacar que as principais atividades econômicas apresentaram [resultados positivos] na geração de emprego [...]." (“Criação de emprego dispara no ABCD em agosto”, Jornal ABCD Maior, 16/09/2009).

\section{O SEMINÁRIO “ABC DO DIÁLOGO E DO DESENVOLVIMENTO"}

O Seminário "ABC do Diálogo e do Desenvolvimento", ocorrido em março de 2009, em São Bernardo do Campo (SP), idealizado e convocado pelo sindicato dos metalúrgicos do $\mathrm{ABC}$, sintetiza o engajamento institucional de duas décadas de iniciativas políticas de enfrentamento da questão do desemprego e da precarização das condições de trabalho. Uma breve descrição desse evento, com seus protagonistas, suas propostas e seus resultados, serve como um retrospecto elucidativo das dinâmicas, conflitos e consensos que se produziram na arena política desse distrito industrial, em função de contextos de crise econômica.

O Seminário realizou-se logo após a deflagração de uma das mais graves crises econômicas do capitalismo mundial, que atingiu as atividades industriais no Brasil ao final de 2008. O desemprego que se confirmou nos meses posteriores a outubro desse mesmo ano alertou os dirigentes do sindicato dos metalúrgicos para a necessidade de interferir na lógica do processo de desenvolvimento econômico regional. Na verdade, o estopim para esta mobilização se deu a partir dos protestos organizados pela base sindical nas portas de fábrica do $A B C$ e nas ruas do município de São Bernardo do Campo (SP), o que, segundo o vice-presidente do sindicato na época, chegou a mobilizar "mais de 18 mil companheiros", que "declararam guerra contra demissões e redução de salários”.

O Seminário não nasceu inicialmente do sindicato. Nasceu em frente à RW, em Diadema, em um protesto contra as demissões. [...] E começamos a discutir com a diretoria, [...] precisamos lançar uma proposta de seminário para mais pessoas... outros grupos se integrarem (Rafael Marques, vice-presidente do sindicato dos metalúrgicos do $\mathrm{ABC}$, em 24/02/2010).

Esse contexto permitiu, então, não só recuperar pautas e práticas sindicais anteriores, exercidas pelo sindicato no ABC dos anos 1990, como, também, acionar diretamente um dos seus principais aliados e ex-dirigente, o Presidente da 
República, Luiz Inácio Lula da Silva. Talvez, por essa razão, o poder de mobilização sindical tenha ultrapassado a esfera regional e o evento ganhado outra dimensão ao propor um amplo debate sobre os efeitos da crise econômica no país. Importantes atores políticos foram convocados e compareceram ao Seminário, como a ministra-chefe da Casa Civil, à época, Dilma Rousseff, o então governador de São Paulo, José Serra e outros membros da administração pública estadual e federal. O Seminário contou, também, com a adesão de atores políticos regionais: a Universidade Federal do ABC, associações, centros comerciais e industriais da região, a Agência de Desenvolvimento Econômico do ABC, a associação das empresas do Polo Petroquímico, além da ANFAVEA e do Sindipeças, representando o setor automotivo.

O grande diferencial do governo Lula foi trazer estes atores para dentro da vida do País, abrir o diálogo e construir políticas conjuntas. No ABCD, nós conquistamos esta autoridade. O Sindicato dos Metalúrgicos do ABC é uma instituição da Região, a comunidade nos entende e quer nos ouvir. Nós criamos historicamente espaços de diálogo de onde surgiram sugestões importantes mesmo em momentos de crise (Para Sérgio Nobre, valorizar salário é garantir desenvolvimento, ABCD Maior, 03/08/2009).

A ação sindical envolveu, também, a administração pública regional. $\mathrm{O}$ fato de o prefeito de São Bernardo do Campo ser um ex-sindicalista metalúrgico, e com experiência adquirida como dirigente sindical durante a crise econômica dos anos 1990 no ABC, consolidou o apoio à ideia desse evento.

OSeminário contou com a presença de mais de 1.500 pessoas. Foi estruturado em grupos de debate sobre os principais problemas da região e refletiu a complexidade de interesses dos diversos setores econômicos ali presentes: problemas de crédito; acesso a mercados e potencialidades regionais com vistas à geração de empregos, e aumento da renda e da competitividade local; tributos e questão fiscal; desemprego; e relações de trabalho e trabalho decente. Ao final, uma carta resumo foi enviada ao Presidente da República, apresentan- do demandas e pedindo soluções. ${ }^{9}$

Após o evento, as avaliações foram, majoritariamente, no sentido de reconhecer avanços: em políticas públicas; no exercício de mecanismos de pressão sobre as administrações municipal, estadual e federal; na possibilidade de acordos mais compreensivos sobre a manutenção de empregos com empresários; no estímulo aos arranjos produtivos locais envolvendo pequenas e médias empresas; na preocupação com a qualidade do trabalho e na formação mais eficiente do jovem trabalhador. Segundo o presidente, à época, do sindicato dos metalúrgicos, Sérgio Nobre,

a gente sabia que o seminário não apontaria uma saída imediata para a crise. Seu grande mérito foi juntar atores econômicos e políticos em torno de uma agenda de negociação. A maior parte das propostas apresentadas depende de ações do setor público e esse é o foco da Câmara Regional. Temos a chance de uma participação efetiva, não só para discutir como superar a crise, mas também discutir como é possível melhorar o ABC. [...] Não é qualquer um que consegue juntar tantas pessoas com tamanha representatividade empresários, trabalhadores e três esferas do poder público - para discutir problemas comuns. Nós conseguimos (Tribuna Metalúrgica - Sindicato dos Metalúrgicos do ABC, 17/03/2009).

9 Trechos da carta: Exmo. Sr. Luiz Inácio Lula da Silva Presidente da República Federativa do Brasil

A Região do Grande ABC, que vem mantendo diálogo constante com Vossa Excelência desde o início de seu primeiro mandato, volta a solicitar sua atenção em um momento em que o Brasil começa a superar os efeitos da crise econômica internacional. [...].

A Região vem sendo beneficiado por várias medidas do Governo Federal desde 2003. Diversos pleitos regionais foram atendidos [...].

Entre os anos de 2003 e 2008, foram gerados na região 173 mil novos postos de trabalho formais, revertendo a tendência anterior e levando a taxa de desemprego no período a quase metade, de $18,1 \%$ a $10,0 \%$.

Apesar da evolução positiva dos indicadores socioeconômicos regionais no período citado, a partir de outubro de 2008 os efeitos da crise internacional se fizeram sentir no Grande ABC [...].

O Grande ABC não está inerte. Face ao novo contexto, mostrou-se mais uma vez capaz de agir como arranjo social articulado em busca de alternativas de enfrentamento das dificuldades. Esse foi o motor do Seminário "O ABC do Diálogo e do Desenvolvimento" [...]. Soluções criativas e compromissos comuns foram adotados na ocasião e estão em andamento. Dando continuidade a esse processo, os representantes da região dirigem-se a V. Excia., resgatando as demandas ainda pendentes e complementando-as. [...]

O Grande ABC conta, mais uma vez, com a atenção e o apoio de V. Excia. Consórcio Intermunicipal do Grande ABC (25 de agosto de 2009). 
Para o vice-presidente do sindicato, o Seminário teve o efeito de recuperar atividades voltadas para o desenvolvimento regional, que vinham passando por diversos ciclos de vitalidade em função das diferenças políticas das administrações públicas ao longo da década de 2000.

Nos últimos cinco anos, seis anos, houve um recuo da integração regional por conta das lideranças que acabaram se consolidando no ABC nas eleições municipais. [...] Uma das propostas do seminário foi rearticular a Câmara Regional (Rafael Marques, 24/02/2010).

Os resultados desse esforço foram incorporados à dinâmica local, e a ênfase regional parece ter se transformado em ponto fundamental nas concepções econômicas e políticas das administrações públicas.

Existe um conceito hoje na região, para qualquer administrador que seja mais ou menos sério, de que ele não pode correr do debate sobre regionalidade. [...] E aquele momento [do seminário] foi importante para criar unidade em torno dessa questão, de que não existe saída para nenhum município ou para nenhuma gestão independente de que partido seja, sozinho (Wagner Santana, Secretário Geral do Sindicato dos Metalúrgicos do ABC, 26/02/2013).

Passados quatro anos da realização do Seminário, já é possível identificar alguns dos seus desdobramentos concretos. No final de 2009, a agenda do trabalho decente foi implantada como fruto do evento.

A primeira Agenda Regional do Trabalho Decente no Brasil começou a ser desenhada no ABC [...], com a assinatura da carta de compromisso e a criação de um grupo de trabalho tripartite formado pelo poder público, sindicatos e empresários para tratar do assunto. [...] O assunto foi para a agenda regional com o seminário $\mathrm{O} A B C$ do Diálogo e do Desenvolvimento, realizado em março, diante da conclusão de que trabalho de qualidade e com direitos é uma maneira de combate à crise e de estímulo ao desenvolvimento social e econômico (Tribuna Metalúrgica - Sindicato dos Metalúrgicos do ABC, 08/12/2009).

Avaliação mais recente confirma o êxito des-

sa iniciativa e sua incorporação às práticas de contratação regionais. O secretário-geral do sindicato dos metalúrgicos do ABC, Wagner Santana (2013), em entrevista, ressalta o fato "da agenda do trabalho decente ter sido adotada pela Câmara Regional (do $A B C$ )", e de que as administrações públicas regionais precisarem "ter aquela agenda em mãos nas suas contratações de terceiros".

Outro empreendimento que se desenvolveu a partir do Seminário de 2009 foi a constituição de um Polo Tecnológico e o incentivo à criação de "Arranjos Produtivos Locais". A interferência local na lógica do sistema produtivo se coloca na tentativa de criar condições para viabilizar a competição das empresas da região com empresas estrangeiras e habilitar o produtor do ABC para a disputa por melhores produtos e qualidade, como é o caso da ferramentaria e das autopeças. Sobre a ferramentaria, diz Wagner Santana (2013), atual secretário geral do sindicato, "conseguimos estruturar uma APL de um setor que estava sendo terceirizado para a China, para a Coréia, para a Alemanha" e sobre as autopeças:

Queremos fazer um debate sobre as autopeças da região, aquelas não sistemistas, que empregam 40 mil trabalhadores, e que condições - aí precisa da intervenção do poder público mesmo - a gente consegue criar para que as empresas brasileiras se tornem competitivas diante das grandes multinacionais fornecedoras.

\section{CONCLUSÃO}

A inclusão do debate sobre desenvolvimento (regional e nacional) à pauta do sindicato dos metalúrgicos do $\mathrm{ABC}$ e, mais ainda, a participação efetiva da entidade sindical em instâncias de mobilização institucional e política fora das fábricas e na formulação de alternativas para as crises produzidas pelas falhas do sistema capitalista com repercussão sobre a vida dos trabalhadores, a nosso ver, constitui uma inovação no contexto do sindicalismo brasileiro das duas últimas décadas por significar uma percepção e um posicionamento que reúne os três pontos da geometria sindical da 
formulação de Hyman (2001), ou seja, uma sensibilidade e uma ação equilibrada na relação com a classe, com o mercado e com a sociedade.

Sem deixar de ser uma agência de classe, confirmada pela permanente manifestação de descontentamento com as empresas em manifestações públicas de protesto e greves, o sindicato dos metalúrgicos negociou, nos contextos de crise e reestruturação produtiva, não só a preservação de empregos, e obteve até mesmo aumentos reais de salário, ${ }^{10}$ Como, também, voltou suas atividades e preocupações também para a sociedade, para as questões sociais como um todo, reivindicando do Estado, através das administrações e suas políticas públicas, uma mudança de foco visando à melhoria das condições de vida da população.

O Seminário "ABC do Diálogo e do Desenvolvimento", por ter sido uma iniciativa sindical e por ter demonstrado um poder de convocação dos diversos setores e interesses da sociedade local e regional para debater uma crise que atingia, mesmo que de forma diferenciada, a todos, confirma um estilo único de sindicalismo, que reúne e combina o acúmulo de um histórico de lutas e de experiências de confronto político de classe, em variados períodos de tempo ao longo do processo de industrialização brasileiro, com uma estratégia de conversão desses recursos políticos em uma expertise para negociar com o mercado e as empresas as questões salariais e de reestruturação produtiva impostas pelas crises do sistema.

A novidade das últimas duas décadas foi a aproximação com as demandas sociais mais amplas da sociedade, ultrapassando os limites da corporação e atuando nas instâncias de decisão sobre políticas sociais e sobre projetos de desen-

${ }^{10}$ Segundo reportagem do jornal Valor Econômico, a representação sindical no ABC garante, não só melhores salários, como uma série de benefícios e segurança aos trabalhadores. "O sindicato conseguiu segurar as demissões na Mercedes em 2012, quando a produção de caminhões despencou. Fechamos um turno de trabalho, mas nindespencou. Fechamos um turno de trabalho, mas nin-
guém foi demitido", diz Wilson José da Silva (montador que trabalha há 18 anos na fábrica da Mercedes-Benz em São Bernardo do Campo). O piso salarial dos metalúrgicos do $\mathrm{ABC}$ está em $\mathrm{R} \$ 1.560$. Esse valor é 131\% maior que o piso dos metalúrgicos no Amazonas, por exemplo, que está em R\$ 675 (Piso do ABC é 131\% maior do que na Amazônia, Valor, 04/02/2013). volvimento regional. O termo "sindicato cidadão", criado no início dos anos 1990, reflete, em parte, essa preocupação. Diríamos que hoje, com o exemplo do Seminário, o debate sobre desenvolvimento e "regionalidade" acrescentou outros elementos às práticas sindicais já voltadas às demandas por melhores condições de habitação, saúde e educação. Está em jogo uma relação mais complexa do sindicato com o território produtivo do qual faz parte, ao se colocar na arena política local como um ator social que reivindica a participação em espaço público nas decisões econômicas e políticas que afetam o bem comum e que contesta, no caso das crises, as justificativas econômicas "moralmente" insustentáveis de atribuir aos trabalhadores os custos dos equívocos do sistema.

A minha tese é que o desenvolvimento econômico é local, tem a sua limitação macroeconômica, é óbvio, taxa de juros, câmbio, política industrial, tem essa limitação macro, mas o território deve, pode fazer muito pelo seu desenvolvimento. Acredito que a mobilização da comunidade é fundamental, ter vários atores, lideranças interessadas em promover o desenvolvimento. Perceber que o desenvolvimentoé uma relação ganho a ganho, onde o público ganha a arrecadação, o trabalhador ganha porque gera mais emprego e o empresário ganha porque gera um ambiente mais favorável para o seu negócio (Paulo Eugênio Pereira Júnior, Secretário Executivo da Agência de Desenvolvimento Econômico do Grande ABC. 27/07/2004).

Se os dados empíricos fornecem elementos para uma interpretação com um caráter de positividade para esta e outras experiências do sindicato dos metalúrgicos do $\mathrm{ABC}$, não há dúvida de que os dilemas presentes na atividade sindical mundial e brasileira permanecem e apontam questões que merecem ser mais discutidas pelos próprios sindicalistas, técnicos e pesquisadores. A produção de conhecimento neste campo de estudos sempre esteve marcada por disputas políticas de interpretação, e as práticas sindicais passam sempre, necessariamente, pelo crivo da luta política e das ênfases variadas que se adequam às concepções do papel que deve desempenhar a instituição sindical no contexto do capitalismo contemporâneo.

A postura pró-ativa do sindicato do $\mathrm{ABC}$, de buscar envolver empresários e administração 
pública na constituição de instâncias de debate sobre desenvolvimento, por exemplo, mantém inalteradas as contradições capital/trabalho e as assimetrias insuperáveis do capitalismo, e poderia significar o abandono da perspectiva de contestação dos anos 1970/1980. As greves e manifestações de protesto, ocorridas na década de 2000 no ABC, não confirmam esta interpretação, além do que, houve ganhos reais de salário, acima da média de outras categorias nesse período. ${ }^{11}$ Ao mesmo tempo, o fortalecimento da instituição sindical ao longo dessas décadas, o que leva a algum tipo de “acomodação”, se comparado com épocas de autoritarismo e confronto político, e que implicaria o descaso com o trabalho de base fabril, também não se confirma. São várias as manifestações de dirigentes sindicais metalúrgicos enfatizando a importância e a legitimidade alcançada pelo trabalho de base, através das comissões de fábrica e comissões sindicais de empresa.

Umex-presidentedosindicatodosmetalúrgicos, com mandato durante a década de 2000, ao ser entrevistado, atribuiu grande significado ao trabalho de base, à proximidade com os trabalhadores dentro das fábricas, pelo fato de ser elemento essencial para manter a confiança e respeitabilidade da instituição sindical.

Entendemos que a estrutura sindical hoje é absolutamente inadequada, cada vez menos capaz de responder à geografia econômica dos setores econômicos e se torna também incapaz de responder às demandas surgidas nas bases dos sindicatos. $\mathrm{E}$ nós, nesta filosofia de um sindicato organizado dentro do local de trabalho, fomos à prática. Então na década de 1980 conquistamos as primeiras comissões de fábrica, o modelo se espalhou. Depois avançamos de modo que a composição da diretoria fosse iniciada pela eleição de comitês

11 "Numa década governada em 80\% do tempo por um exlíder sindical dos metalúrgicos de São Bernardo do Campo (SP), as negociações salariais envolvendo os operários das quatro montadoras da região do ABC paulista registraram o avanço mais expressivo num grupo de quatro categorias tradicionais. Enquanto os petroleiros da Petrobras acumularam ganhos de 1,3\% acima da inflação registrada entre 2000 e 2010 e os bancários viram seus rendimentos reais crescerem $3,4 \%$, os operários das montadoras do ABC registraram ganho real de 37,4\%, mais que o dobro do já expressivo resultado alcançado pelos químicos - $15,2 \%$ acima da inflação no período [...]". (Com Lula em Brasília, reajuste real foi mais elevado no ABC, Valor Econômico, 19/01/2011). sindicais de empresa; hoje temos, $85 \%$ da categoria com representação no local de trabalho. Esta proximidade cotidiana na fábrica nos permite a observação de como está a produção e a economia do nosso setor. Então, de quem a gente compra, para quem a gente vende, os novos modelos de gestão, de tecnologia que vão sendo introduzidos no local de trabalho e as suas consequências. Este foi um dos primeiros sindicatos a discutir para valer os novos métodos de trabalho e a introdução de novas tecnologias. [...] E tínhamos que tomar uma decisão; ou as empresas farão essa reestruturação como bem entenderem, ou o sindicato vai interferir. E nós optamos por interferir (José Lopes Feijó, Presidente do Sindicato dos Metalúrgicos do ABC, 18/06/2004).

Para Bresciani (2004, p. 8), o sindicalismo do ABC se reinventa, sua atuação política se diversificou ao longo dos últimos 25 anos e sua capacidade política, no debate e coordenação da agenda regional do desenvolvimento econômico, apresenta um "adequado equilíbrio no que diz respeito à presença sindical na microesfera do cotidiano produtivo” e na participação dos trabalhadores na transformação dos seus locais de trabalho. Para este autor, a sintonia fina da política sindical, que enfatiza o vínculo entre as duas esferas, a região e o local de trabalho, é que coloca os maiores desafios às lideranças dos trabalhadores na "perspectiva concreta de um desenvolvimento regional efetivamente democrático e inclusivo".

Na sua função de regular a relação de trabalho, o sindicato permanece exercendo sua função de representação, já que não pode "ignorar o mercado". E, como parte da sociedade, necessita, para sua sobrevivência, coexistir com outras instituições e outras constelações de interesse (mesmo com aquelas que certos sindicatos proclamam um antagonismo imutável) (Hyman, 2001, p. 3-4). No caso do ABC, no entanto, o sindicato não pode deixar de ser uma "agência de classe" ao se distinguir dos empregadores pelo fato de incorporar, em sua concepção institucional, os interesses coletivos dos trabalhadores e reafirmar sua identidade coletiva. Em resumo, podemos dizer que a ação sindical dos metalúrgicos do ABC, voltada para a participação política na discussão sobre projetos de desenvolvimento econômico regional (e nacional), contestando decisões que prejudicam a criação e 
manutenção de empregos e que afetam o bem estar e as condições de vida da população em geral, aproxima a instituição das demandas da sociedade e reforça sua legitimidade como instância de representação dos interesses dos trabalhadores.

Recebido para publicação em 30 de março de 2013 Aceito em 14 de junho de 2013

\section{REFERÊNCIAS}

ABRUCIO, Fernando; SOARES, Márcia M. Redes federativas no Brasil: cooperação intermunicipal no Grande ABC. São Paulo: Fundação Konrad Adenauer, Série Pesquisas, 24, 2001.

ALBUQUERQUE, F. La iniciativa de desarrollo regional del "Gran ABC", São Paulo (Brasil). São Paulo: Agência de Desenvolvimento Econômico do Grande ABC e Banco Interamericano de Desenvolvimento, mimeo, 2001.

ANDERSON, Patrícia. Câmaras setoriais: histórico e acordos firmados, 1991/95. Texto para discussão, Rio de Janeiro: IPEA, n. 667, 1999.

ARBIX, Glauco. Uma aposta no futuro: os primeiros anos da câmara setorial da indústria automobilística. São Paulo: Scritta, 1996.

A câmara banida. In: ARBIX, Glauco e ZILBOVICIUS, Mauro (Orgs.). De JK a FHC: a reinvenção dos carros. São Paulo: Scritta, 1997.

BONIFACE, D. Post-statist development iniciatives in Greater 'ABC' São Paulo: a case study in innovation. Tese (Doutorado em Ciência Política). Urbana-Champaign: University of Illinois, 2001.

BRESCIANI, Luís Paulo. Instituicões, agenda regional, desenvolvimento econômico e política sindical no Grande $A B C$ : os desafios do equilíbrio entre (macro) esfera institucional regional e a (micro) esfera cotidiana produtiva. Caxambu: Anpocs, 2004.

; BENITES FILHO, Flávio A. Negociações tripartites na Itália e no Brasil: o acordo nacional e as câmaras setoriais. São Paulo: LTr, 1995.

CADERNO DE TESES. Construindo um Brasil justo e democrático: emprego e trabalho decente. VI CONGRESSO DOS METALÚRGICOS DO ABC. São Bernardo do Campo: sindicato dos metalúrgicos do ABC, 2009.

CAMARGO, Zeíra M. O Sindicato dos Metalúrgicos do ABC e as ações regionais na década de 90. Dissertação (Mestrado em ad̉ministração). São Caetano do Sul: Centro Universitário Municipal de São Caetano do Sul - IMES, 2003.

CARDOSO, Adalberto M. Rompendo o círculo de ferro: impactos do acordo das montadoras nas relações de trabalho no setor automotivo brasileiro. In: OLIVEIRA, Francisco e COMIM, Álvaro (Orgs.). Os cavaleiros do antiapocalipse: trabalho e política na indústria automobilística. São Paulo: Cebrap/ Entrelinhas, 1999a.

; COMIN, Alvaro A. Câmaras Setoriais, modernização produtiva e democratização nas relações entre capital e trabalho no Brasil. In: CASTRO, Nadya de Araújo (Org.) A máquina e o equilibrista. São Paulo: Paz e Terra, 1995.
CARTA DO ABC, 25/08/2009.

CONCEIÇÃO, Jefferson José da. Quando o apito da fábrica silencia - sindicatos, empresas e poder público diante do fechamento de industrias e da eliminaçấo de empregos na região do ABC. São Paulo: ABCD Maior, 2008.

CONSÓRCIO INTERMUNICIPAL DO GRANDE ABC, Comunidade Cidadã, 2006. http://www.consorcioabc.org.br/ comunidade.htm.

DANIEL, Celso. Gestão compartilhada, limites e possibilidades: a experiência do Grande ABC. In: Consórcio: uma forma de cooperação intermunicipal. São Paulo: Fundação Prefeito Faria Lima/Cepam, 2001a.

- Uma experiência de desenvolvimento econômico local: a Câmara Regional do Grande ABC. In GUIMARÁES, Nadya A.; MARTIN, Scott (Orgs). Competitividade e desenvolvimento: atores e instituições locais. São Paulo: SENAC, 2001b.

; SOMEKH, Nadia. Novas estratégias de ação regional: a experiência recente da Câmara do Grande ABC. Porto Alegre: Anais do Encontro Nacional da ANPUR, 1999.

DE SARDAN, Jean Pierre Olivier. Anthropology and development: understanding contemporary social change. London/New York: Zed Books, 2005.

DINIZ, Eli. Articulação dos atores na implantação da política industrial: a experiência das câmaras setoriais: retrocesso ou avanco na transicão para um novo modelo? Campinas: IE-UNICAMP / IEI-UFRJ / FDC / FUNCEX. Nota Técnica do Estudo de Competitividade da Indústria Brasileira, 1993.

FAIRBROTHER, Peter; WEBSTER, Eddie. Social Movement Unionism: questions and possibilities. Employee Responsibilities and Rights Journal, v. 20, n. 4, p. 309-313, 2008.

GOMES, Edgar da N. Planejamento econômico local, desenvolvimento e participação social: a experiência das cidades do Grande ABC Paulista. Dissertação (Mestrado em economia). São Paulo: PUC-SP, 1999.

GUIMARÃES, Nadya; COMIN, Álvaro A.; LEITE, Márcia de Paula. Por um jogo de soma positiva: conciliando competitividade e proteção ao emprego em experiências inovadoras de negociação no Brasil. In: GUMARÁES, Nadya e SCOTT, Martin (Orgs). Competitividade e desenvolvimento: atores e instituições locais. São Paulo: SENAC, 2001.

HORTA, Celso A. O braço "direito" do Grande $A B C$ : um estudo de caso do Diário do Grande ABC e sua insercão na regionalidade e nos conflitos das relações de trabalho. Dissertação (Mestrado em administração). São Caetano do Sul: Centro Universitário Municipal de São Caetano do Sul - IMES. , 2003.

HYMAN, Richard. Understanding European Trade Unionism. London: Sage, 2001.

KLINK, Jeroen. A cidade-região: regionalismo e reestruturação no grande ABC paulista. Rio de Janeiro: DP\&A, 2001.

O novo regionalismo: o caso da região do Grande $\overline{A B}$ C. Tese (Doutorado em Arquitetura e Urbanismo). São Paulo: Universidade de São Paulo, 2000.

LEITE, Márcia de P. Nova estrutura industrial e trabalho: a experiência da Câmara Regional do Grande ABC no Brasil. Campinas: DECISA/UNICAMP, mimeo, 1999.

MOODY, Kim. Workers in a lean world: Unions in the International Economy. London: Verso, 1997.

MUNCK, R. Globalisation and labour: the new 'great transformation'. London: Zed Books, 2002. 
OLIVEIRA, Francisco. O acordo das montadoras: quanto melhor, melhor. Novos Estudos CEBRAP, 36, 1993

; FARIA,Vilmar; GIANNOTTI, J. Arthur. Os cavaleiros do antiapocalipse: o acordo das montadoras. São Paulo: CEBRAP - projeto de pesquisa, 1992.

PETROLLI, Valdenízio. Diário do Grande ABC: a construção de um jornal regional. Tese (Doutorado em Teoria e Ensino da Comunicacão). São Bernardo do Campo: Universidade Metodista de São Paulo - UMESP. , 2000.

RAMALHO, José Ricardo; RODRIGUES, Iram J.; CONCEIÇÃO, Jefferson J. Reestruturação industrial, sindicato e território - alternativas políticas em momentos de crise na região do ABC em São Paulo - Brasil. Revista Crítica de Ciências Sociais, Coimbra, Universidade de Coimbra, n. 85, 2009.

; RODRIGUES, Iram J. Sindicato, crise econômica e estratégias regionais - novas dimensões da participação política no ABC Paulista. Caderno CRH, Salvador, v. 23, n. 59, p. 339-351, Maio/Ago. 2010.

REVISTA ABC DO DIÁLOGO E DO DESENVOLVIMENTO. A região unida para enfrentar a crise. São Bernardo do Campo: Agência de Desenvolvimento Econômico do Grande ABC e Imprensa do Sindicato dos Metalúrgicos do ABC, 2009

REIS, Regina C. dos. Articulação política regional: a experiência do Grande ABC, 1990-2005. Tese (Doutorado em Ciências Sociais). São Paulo: PUC-SP. 2005.

RODRIGUES, Iram Jácome. O sindicalismo brasileiro: da confrontação à cooperação conflitiva. São Paulo: Revista São Paulo em Perspectiva, v. 9, n. 3, jul/set/1995, p. 116126, 1995.

Sindicalismo e política - a trajetória da CUT (1983-2003). São Paulo: LTr, 2a . Edição, 2011.

A dimensão regional da ação sindical: os metalúrgicos do ABC. Estudos de Sociologia. Araraquara: FCL - UNESP, v. 11, n. 21, $2^{\circ}$. Semestre de 2006, p. 73-96, 2006.
; RAMALHO, José R. Trabalho e Sindicato em antigos e novos territórios produtivos: comparacões entre o ABC paulista e o Sul fluminense. São Paulo: Annablume, 2007.

SEIDMAN, Gay. Manufacturing militance: workers' movements in Brazil and South Africa, 1970-1985. Berkeley: California University Press, 1994.

SILVA, Leonardo Mello. A generalização difícil: a vida breve da Câmara Setorial do complexo químico seguida do estudo de seus impactos em duas grandes empresas do ramo em São Paulo. Tese (Doutorado em Sociologia). São Paulo: Universidade de São Paulo, 1997

VÉRAS DE OLIVEIRA, Roberto. Sindicalismo e Democracia no Brasil - do novo sindicalismo ao sindicato cidadão. São Paulo: Annablume, 2011.

WATERMAN, Peter. Social Movement Unionism in question: contribution to a Symposium. Employee Responsibilities and Rights Journal, v. 20, n. 4, p. 303308, 2008.

Globalisation, social movements and the new internationalism. London: Mansell, 1998.

\section{ENTREVISTAS}

Wagner Santana, Secretário do Sindicato dos Metalúrgicos do ABC, em 26/02/2013.

Rafael Marques, Vice-presidente do Sindicato dos Metalúrgicos do ABC, em 24/02/2010.

José Lopes Feijó, Presidente do Sindicato dos Metalúrgicos do ABC, em 18/06/2004.

Paulo Eugênio Pereira Júnior, Secretário Executivo da Agência de Desenvolvimento Econômico do Grande ABC, em 27/07/2004. 


\section{UNIONS, DEVELOPMENT AND WORK: economic crisis and political action in the $A B C$ Region}

\author{
José Ricardo Ramalho \\ Iram Jácome Rodrigues
}

The goal of this text is to discuss and problematize the new practices by the metal worker unionists in São Paulo's ABC region, which implies the direct involvement of the entities which represent workers outside the actual factory in the debate regarding development strategies and their ramifications in the regional context of a global economy. We will analyze union actions during two different periods (the 1990s and $2000-2009$ ) and as a synthesis of this process, we will focus on a political event organized and held by the metal workers' union in 2009, a seminar called "The ABC of Dialog and Development", which reveals the different insertions and perspectives of the social actors at the local, regional and national levels in the search for alternatives regarding the worldwide economic crisis of 2008. The event exemplifies a public meeting which despite not doing away with the contradictions and conflicts of a social reality marked by the asymmetry of positions in the social structure, created a moment of temporary consensus regarding the threats of a setting hostile to workers.

KEY WorDS: Union Action. Regional Development. São Paulo’s ABC. Economic Crisis.

\section{SYNDICAT, DÉVELOPPEMENT ET TRAVAIL: la crise économique et l'action politique dans la région de l'ABC}

\author{
José Ricardo Ramalho \\ Iram Jácome Rodrigues
}

L’objectif de cet article est de discuter et de remettre en question les nouvelles pratiques syndicales des métallurgistes de la région de l'ABC pauliste. Ceci fait que les organes représentatifs des travailleurs non-manufacturiers sont directement concernés et mène à un débat sur les stratégies de développement et leurs conséquences dans les contextes régionaux d'une économie mondialisée. Nous analyserons l'action syndicale sur deux périodes distinctes (les décennies de 1990 et 2000) et nous mettrons en évidence, comme une synthèse de ce processus, la réalisation d'un événement politique organisé par le syndicat des métallurgistes en 2009, le Séminaire "L'ABC du Dialogue et du Développement”, qui révèle les différentes insertions et perspectives des acteurs sociaux locaux, régionaux et nationaux dans la recherche d'alternatives à la crise mondiale de 2008. C'est un exemple de réunion publique qui, sans éliminer les contradictions et les conflits d'une réalité sociale marquée par des positions asymétriques dans la structure sociale, a créé un moment de consensus provisoire face aux menaces d'une conjoncture hostile aux travailleurs.

Mots-CLÉs: Action syndicale. Développement régional. Région de l'ABC pauliste. Crise économique.

José Ricardo Ramalho - Doutor em Ciências Sociais (Ciência Política) na Universidade de São Paulo, e pósdoutorados na Universidade de Londres (UK) e na Universidade de Manchester (UK). Professor titular do Departamento de Sociologia e do Programa de Pós-Graduação em Sociologia e Antropologia da Universidade Federal do Rio de Janeiro (UFRJ). Pesquisador do CNPQ. Sua atuação acadêmica está mais voltada para a área da Sociologia do Trabalho e seus principais temas de pesquisa são: relações de trabalho na indústria; sindicato e sindicalismo; reestruturação produtiva e distritos industriais; trabalho, emprego e desenvolvimento econômico regional e local; identidade operária. Autor e coautor de várias publicações em revistas científicas e livros. Entre estes, Estado Patrão e Luta Operária: o caso FNM. Rio de Janeiro, Paz e Terra, 1989; Trabalho e Sindicato em antigos e novos territórios produtivos. São Paulo: Annablume, 2007.

Iram Jácome Rodrigues - Doutor em Sociologia. Professor Associado (Livre-Docente) do Departamento de Economia da Universidade de São Paulo e do Programa de Pós-Graduação em Sociologia da Universidade de São Paulo (PPGS-USP). Atua na área de Sociologia, com ênfase em Sociologia do Trabalho, principalmente nos seguintes temas: ação coletiva, sindicalismo e desenvolvimento regional; relações de trabalho e organização de interesses; sindicalismo e política; trabalho e sindicalismo; emprego, desenvolvimento econômico local e regional. Autor e coautor de várias publicações em revistas científicas e livros. Entre estes, Sindicalismo e Política: a trajetória da CUT (1983-1993). $2^{\circ}$. ed. São Paulo: LTr, 2011; Trabalho e Sindicato em antigos e novos territórios produtivos. São Paulo: Annablume, 2007. 
